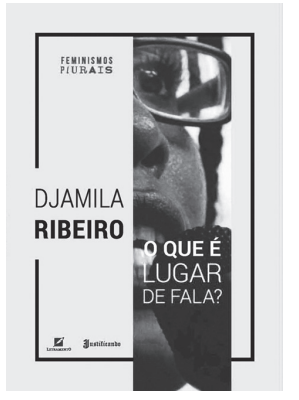

\title{
Ribeiro D. O que é lugar de fala?
}

\author{
Gilney Costa Santos ${ }^{1}$
}

DOI: 10.1590/0103-11042019S826

FILHA DE ESTIVADOR E DE EMPREGADA DOMÉSTICA, Djamila Taís Ribeiro dos Santos, nascida na Baixada Santista, São Paulo, em $1^{\circ}$ de agosto de 1980, figura hoje entre uma das principais intelectuais negras e feminista do Brasil. Graduada em filosofia, em 2012, e mestra em Filosofia Política, em 2015, ambos os títulos pela Universidade Federal de São Paulo. Desde cedo, Djamila Ribeiro habituara-se a refletir sobre a questão social dos corpos negros por influência de seu pai, militante do movimento negro e um dos fundadores do Partido Comunista de Santos ${ }^{1}$. Em 2015, assumiu como secretária-adjunta a pasta de Direitos Humanos e Cidadania da cidade de São Paulo, experiência que marcou sua trajetória por ter possibilitado refletir sobre os constrangimentos e a solidão que a mulher negra vivencia nos espaços de poder ${ }^{2}$.

'O que é lugar de fala?'3 , pergunta que dá título ao livro, representa uma inflexão no modo de produzir e divulgar conhecimentos científicos no mercado editorial brasileiro. O livro integra a coleção 'Feminismos plurais', também coordenada por Djamila; em que, na capa de cada obra, o leitor se depara com fotos das/dos autoras/autores como forma de mostrar que se trata de trabalhos produzidos por mulheres ou homens negros/negras e/ou indígenas.

De modo geral, 'O que é lugar de fala?' se destaca por sua intencionalidade e ambição: ser uma obra didática capaz de dialogar desde a/o leitora/leitor curioso até a/o mais especialista, e ser acessível no sentido de democratizar o livro/conhecimento produzido por pessoas negras, estando presente nas redes de livrarias a um preço razoavelmente baixo. Além disso, a maior parte das referências que dão sustentação às discussões do livro é de autoras/autores negras/ negros, como forma de dizer que há homens e mulheres negras pensando a temática no contexto da sociedade brasileira e do mundo, a partir de outros referenciais, marcos históricos e epistemologias, tornando visível autoras/autores e obras esquecidas/esquecidos na história.

'O que é lugar de fala?' enfrenta o desafio de pensar quem pode (ou não) falar no contexto de um regime patriarcal, colonial, racista e classista que historicamente marca a formação da sociedade brasileira. Para tanto, o livro está estruturado em cinco capítulos com relativa autonomia para a compreensão da temática, de modo que o leitor pode montar o seu

'Fundação Oswaldo Cruz (Fiocruz), Escola Nacional de Saúde Pública Sergio Arouca (Ensp) - Rio de Janeiro (RJ), Brasil. gilney.costa@yahoo.com.br esquema de leitura: se começará pelo meio, pelo fim ou se fará leitura sequenciais dos capítulos.

Do ponto de vista epistemológico, 'lugar de fala' é um conceito de origem imprecisa, que, segundo Djamila, parece estar ancorado no movimento 'feminist stand point', isto é, na compreensão de um 'ponto de vista feminista' que articula teoria racial crítica e pensamento decolonial. 
O livro recusa a tese de que o feminismo negro opera cisões no movimento de mulheres e aposta no estudo interseccional das relações de raça, classe e gênero como forma de compreender o lugar social ocupado pelo corpo pobre, negro, feminino, indígena, LGBTQI+. Nessa perspectiva, a interface entre o 'ponto de vista feminista' e o 'lugar de fala' está na articulação de diferentes pontos de análises, dentre os quais caberia destacar: a) quem (pode) fala(r); b) sobre o que está falando; c) para quem; e d) com quais interesses.

'Lugar de fala' é assumido por Djamila como lugar no qual, do ponto de vista discursivo, os corpos subalternizados reivindicam sua existência. Não por acaso, Djamila inicia o debate recuperando a trajetória do feminismo negro como movimento que se constituiu a partir da reflexão coletiva de mulheres negras sobre a sua condição de corpos oprimidos na busca pelo direito de falar/existir.

Nesse sentido, 'lugar de fala' possibilita um olhar sobre as experiências dos corpos subalternizados valorizando o lugar comum, compreendido como locus social que atravessa as experiências coletivizadas desses corpos. No livro, Djamila reconhece que 'lugar de fala' é objeto de disputas antagônicas. Há quem considere 'lugar de fala' como a expressão de vozes individualizadas, sem qualquer referência às vivências coletivas compartilhadas por grupos. Há, ainda, os que advogam 'lugar de fala' como uma construção social de coletivos que reivindicam humanidades histórica e sistematicamente negadas localizando nas experiências vivenciadas marcas de opressão, subalternidade e violências.

Não se trata, portanto, de afirmar experiências individuais, e, sim, entender como o lugar social que certos grupos ocupam implica na forma de caminhar pela vida. É a essa perspectiva de 'lugar de fala' como construção social que Djamila e o livro estão posicionados.

Desse ponto de vista, os estudos centrados nas análises dos lugares de fala colocam em destaque as estruturas sociais que atravessam as experiências coletivas vivenciadas por grupos. Trata-se de problematizar as relações sociais de sexo/gênero, raça e classe social a partir de uma perspectiva estrutural, e não pós-moderna/identitária, como equivocadamente a crítica em relação ao conceito tem sido apresentada. Dito de outro modo, os tipos de opressões e controles que operam, por exemplo, sobre a população em situação de rua, ainda que a experiência de racismo institucional seja da ordem do singular, revelam profundas relações com um passado escravocrata-colonial-patriarcal.

'Lugar de fala' é também o entendimento de que todas as pessoas estão inscritas em determinados contextos discursivos, inclusive as que sempre estiveram no diagrama saber-poder, e pode expressá-lo para qualquer tema. Assim, o homem branco pode refletir criticamente sobre mulheres e racismo, mas o fará a partir do lugar que ocupa, isto é, do lugar de quem foi/é beneficiado por essa estrutura. Contudo, sua fala também jamais será equivalente à da mulher negra; e não se pode querer que seja, uma vez que é impossível assumir a fala do outro.

Se, por um lado, lugar de fala reconhece os contextos discursivos nos quais as pessoas estão inscritas, por outro, a representatividade significa a possibilidade de pensar criticamente esse lugar reconhecendo nele fronteiras que devem ser respeitadas. Ou seja, representatividade, ao mesmo tempo que delimita fronteiras, possibilita o trânsito entre elas.

Nessa perspectiva, é possível que uma travesti negra não se sinta representada por um homem branco cis, mas é possível que esse homem possa teorizar sobre o cotidiano de vida das pessoas trans a partir do lugar que ele ocupa, posto que a luta pela representatividade não exclui a responsabilização de quem historicamente ocupa espaços privilegiados. Dito de outro modo, a representatividade não pode essencializar o debate político, como se só o corpo subalternizado pudesse falar sobre racismo, sexismo e desigualdade.

No campo da saúde pública/coletiva, 'lugar de fala' pode ser potente à medida que 
*Orcid (Open Researcher and Contributor ID). desestabilize práticas inaugurando espaços para escutar, por exemplo, o que significa ser mulher/mãe negra em situação de rua usuária de substância psicoativa ou ainda ser um corpo negro que habita na favela. Desse modo, princípios como integralidade e equidade poderão se materializar em formas de cuidado, o cuidado possível no contexto de fala do/da profissional de saúde e do/da usuária/usuário.

A leitura dessa obra é altamente recomendada a quem se interesse pelas discussões de classe, raça e gênero por contar a "história que a história não conta" ${ }^{4}$. Especialmente, aos profissionais de saúde e/ou militantes da Reforma Sanitária Brasileira, por sua capacidade de inserir novos marcos éticos e humanos, que cativem corações e mentes dispostos a lutar por outro modelo de vida, sociedade e Outros Olhares para Reforma.

Este texto é dedicado a Evaldo dos Santos, homem negro e músico que teve seu carro alvejado por 62 dos 257 tiros de fuzis e pistolas disparados em uma área de favela, no Rio de
Janeiro, por militares do exército brasileiro. É dedicado, também, a Luciano Macedo, homem negro e catador de latinhas que tentou socorrer Evaldo, ambos vítimas do racismo de Estado.

\section{Agradecimentos}

O autor agradece ao Programa Bolsa Nota 10 da Fundação Carlos Chagas Filho de Amparo à Pesquisa do Estado do Rio de Janeiro (Faperj); Programa de Excelência Acadêmica/ Coordenação de Aperfeiçoamento de Pessoal de Nível de Superior (Proex/Capes) pelo financiamento da bolsa de Doutorado em Saúde Pública para a realização do estudo.

\section{Colaborador}

Santos GC (0000-0002-0673-7869)*é responsável pela elaboração do manuscrito.

\section{Referências}

1. Ribeiro D. Quem tem medo do feminismo negro? São Paulo: Companhia das Letras; 2018.

2. Mendonça T. Djamila Ribeiro: "não dá pra tratar as opressões de forma isolada” [internet]. 2019. [acesso em 2019 maio 13]. Disponível em: http://www.atarde. uol.com.br/muito/noticias/2053243-djamila-ribeiro-nao-da-para-tratar-as-opressoes-de-forma-isolada.

3. Ribeiro D. O que é lugar de fala? Belo Horizonte: Letramento; 2017. (Feminismos plurais).
4. Firmino D, Domêncio D, Mama, et al. História pra ninar gente grande. Rio de Janeiro: Mangueira; 2019. [acesso em 2019 jul 24] Disponível em: http://www. mangueira.com.br/sambaenredo.

\footnotetext{
Recebido em 01/06/2019

Aprovado em 02/08/2019

Conflito de interesses: inexistente

Suporte financeiro: Programa Bolsa Nota 10 da Fundação Carlos Chagas Filho de Amparo à Pesquisa do Estado do Rio de Janeiro

(Faperj); Programa de Excelência Acadêmica/Coordenação de

Aperfeiçoamento de Pessoal de Nível de Superior (Proex/Capes)
} 